\title{
SOGC urges national enquiry into maternal deaths
}

Cite as: CMAJ 2017 July 24;189:E975-6. doi: 10.1503/cmaj.1095451

Posted on cmajnews.com on July 5, 2017.

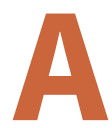
few weeks after giving birth to her third child, a woman is found alone on a bridge with a brand new rope. She's taken to the emergency department where she explains that she's had postpartum depression before and already has a prescription for antidepressants. She doesn't seem intent on killing herself, so she's discharged. A month later, after her suicide, a review concludes that the woman's death was completely unexpected.

Few women in developed countries expect to die during or in the year after pregnancy, and fewer still might expect the cause to be suicide, as in this case reported to a longstanding confidential enquiry in the United Kingdom. But according to the enquiry, suicide remains a leading direct cause of maternal mortality, and even greater numbers of women die from indirect causes, such as heart conditions or infections exacerbated by pregnancy. Whatever the cause, it's estimated that about two in five of these deaths are preventable.

Canada likely faces the same challenges, says Dr. Jon Barrett, chief of maternal-fetal medicine at Sunnybrook Hospital in Toronto. "The trouble is that we don't know." There is no national, case-by-case examination of maternal deaths that could highlight potential gaps in care, and it's likely that Canada's reported maternal mortality rate underestimates the scope of the problem, he explains.

The Society of Obstetricians and Gynaecologists of Canada (SOGC) has once again taken up the call for a UK-style enquiry, says Barrett, a board member. "That's got to be our goal and I know SOGC is intent on working to make it happen."

There's reason to believe that serious complications of pregnancy and maternal deaths may have increased slightly, or at least plateaued, after decades of decline. According to the Organisation for Economic Co-operation and Development, Canada reported a low of 2.5 maternal deaths per 100000 live births in 1990, but in the following years, the rate steadily increased to a peak of nine in 2008, before dropping off to 5.7 at last count in 2013. The World Health Organization reported a higher rate for Canada of seven deaths per 100000 in 1990, which hadn't changed at last count in 2015.

However, these rates are based on vital statistics data that have been shown to underestimate maternal deaths by $12 \%$ to $70 \%$ compared with hospitalization data. The count excludes data from Quebec, as well as deaths more than 42 days to a year after pregnancy, which means many suicides may be missed - if they're even reported as maternal deaths.
Meanwhile, factors that complicate pregnancy are on the rise, from maternal age and obesity, to rates of cesarean section. And for every death, the UK enquiry has found there are far more cases of severe morbidity. "The lessons I think we can take from these near misses are huge," says Barrett.

Casting a wider net to more accurately capture maternal deaths is the first step, says Marian Knight, who leads the UK enquiry. "If we were to rely solely on our routine vital statistics data we'd only identify half of our maternal deaths," Knight explained at the SOGC's recent annual conference in Ottawa.

About two-thirds of deaths are reported directly to the enquiry by hospital staff, she said. "However, we get additional reports from pathologists, coro-

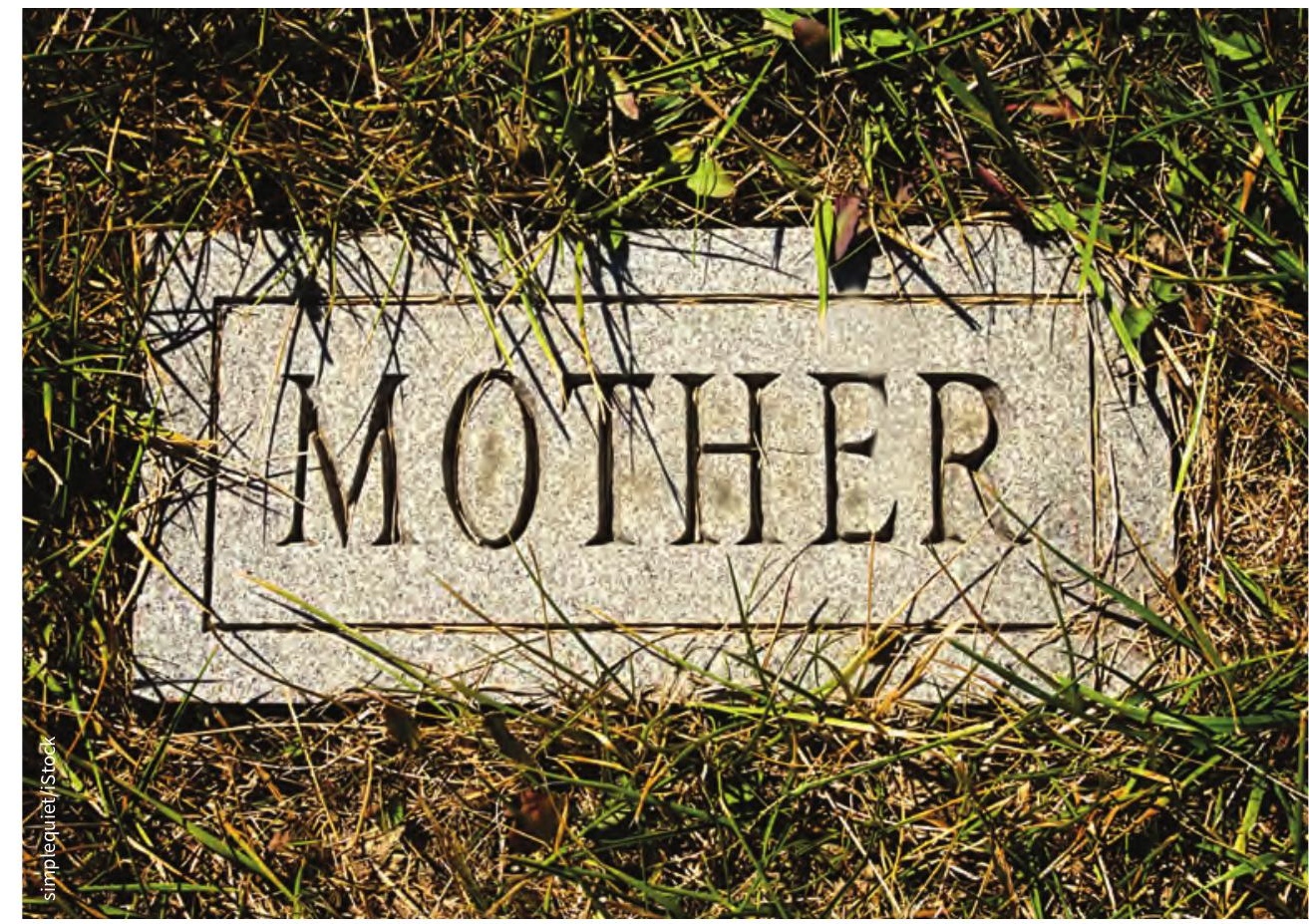

Canada's maternal death rate may be low, but we'll have to delve deeper to curb preventable tragedies. 
ners, midwives, and also unfortunately, the media," among other sources. The enquiry also links birth registration data with deaths in women of reproductive age to detect those that occur up to a year after pregnancy.

Knight said this approach provides a more accurate estimate of maternal deaths in the UK, which was pegged at 8.5 per 100000 births in 2016. "It also means I spend a lot of time justifying to the media why our death rate is apparently higher than countries such as Belarus, because we look for and find all of our maternal deaths, or we certainly try."

However, a national rate can only tell you so much, particularly when it comes to disadvantaged groups who suffer much higher maternal mortality rates. That's where the investigative aspect of the enquiry comes in, said Knight. For each case, "we collect copies of the woman's entire medical record, her post-mortem autopsy report, and we also get reports from local clinicians involved in her care about what they feel should have been done differently." These records are anonymized and each case is reviewed by 10 to 15 multidisciplinary experts. Those reviews are then combined into annual reports. All told, about 600 people are involved in the process, and only four are paid. "This works because of people's good will," Knight said.

The enquiry's reports have helped the UK achieve a year-on-year decline in maternal deaths by revealing unexpected blind spots in maternal care. In the case of suicide, "we were able to highlight that $40 \%$ of the women who died would still not have been able to access specialist perinatal mental health care if they became ill today," even though they "presented time and time again to different bits of the health care system," Knight said. This prompted the government to invest $£ 175$ million (about $\$ 292.3$ million) to improve access.
Barrett argues there's no reason why Canada can't follow the UK example. However, previous calls for a Canadian enquiry haven't amounted to much in the past decade. Barrett partly attributes this inertia to fears about the legal ramifications of tracking missteps in care that cause maternal deaths, as well as the usual jurisdictional barriers. "The UK has the legal ability to collect this data on a national level," he explains. "We don't have that because there are problems about sending data from one province to another."

Neither barrier is insurmountable, he says. The UK handles the medico-legal issues by anonymizing the data, and Canada could do the same, working around the jurisdictional issues by compiling reports "within the provinces."

"Even if it's province by province, even if we can't get the whole country covered, we've got to start somewhere," Barrett says.

Lauren Vogel, CMAJ 